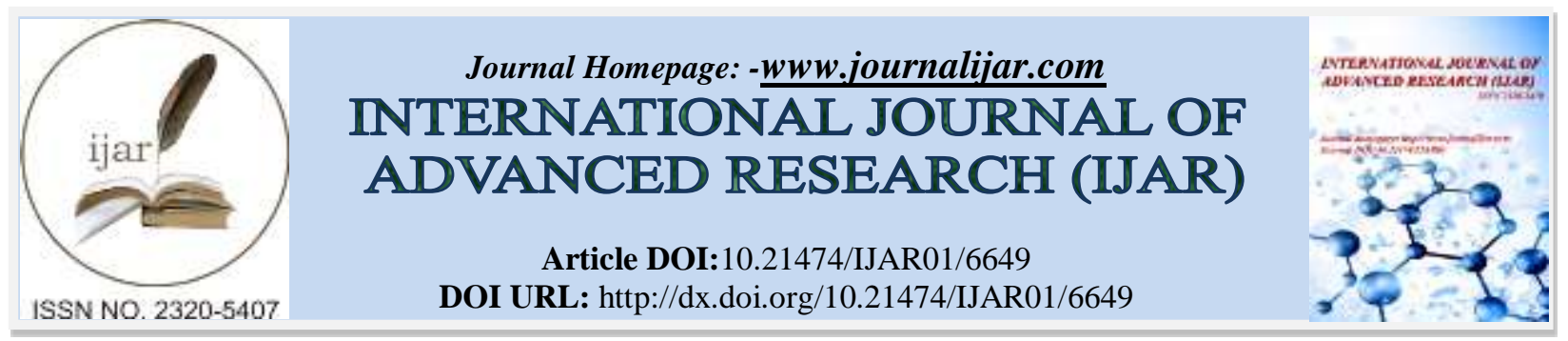

\title{
RESEARCH ARTICLE PREVALENCE AND RISK FACTORS OF MISTREATMENT IN ELDERLY PEOPLE.
}

\section{Ana Rosa Can Valle ${ }^{1}$, Jaqueline Guadalupe Guerrero Ceh $^{1}$, Betty Sarabia Alcocer ${ }^{2}$, Fajime Cu Quijano ${ }^{3}$, Victoria Guadalupe Pech Chan ${ }^{4}$ and Karla Doricela Haaz Yam${ }^{4}$.}

1. Professor and Researcher at the Faculty of Nursing at the Autonomous University of Campeche.

2. Professor and Researcher at the Faculty of Medicine of the Autonomous University of Campeche.

3. Professor and Researcher at the Faculty of social Sciences of the Autonomous University of Campeche.

4. Interns of the bachelor of gerontology at the Faculty of Nursing at the Autonomous University of Campeche.

\section{Manuscript Info}

Manuscript History

Received: 03 January 2018

Final Accepted: 05 February 2018

Published: March 2018

\section{Abstract}

The abuse violates the rights and dignity as a result of the abuse of power towards a person who is in a situation of disadvantage and inferiority due to its limitations, whether due to age, gender or loss of abilities. Victims of violence are found in all age groups, with the abuse of women, children and the elderly being especially recognized. Violence includes psychological, physical and sexual assaults, abandonment and, especially in the elderly, the economic or patrimonial abuse by relatives or other persons outside the family is added. Objective. Identify the level of prevalence of abuse in the elderly. Method. The study of this research is descriptive, with a quantitative, transversal approach. Subjects 60 seniors from different Institutions. Instrument. Geriatric Scale of Elder Abuse, consists of five sections: physical, psychological, negligence, economic and sexual. Results Negligence, 53 seniors commented that they have not stopped providing clothes, shoes, among others and 7 of them say that if and if they have stopped supplying the medication they need, 45 replied that no but 6 of them say that Yes, in the question, this section is the most relevant. Conclusions. As a final result of this investigation, we found that $25 \%$ of older adults belonging to a governmental institution in the state of San Francisco de Campeche have some type of abuse. Of which the psychological abuse was the most prevalent with $40 \%$.

Copy Right, IJAR, 2018,. All rights reserved.

\section{Introduction:-}

Mistreatment in elderly people violates the rights and dignity as a consequence of the abuse of power towards a person who is in a situation of disadvantage and inferiority due to its limitations, age, gender or loss of abilities. Victims of violence are found in all age groups, especially in women, children and elderly people. Violence includes psychological, physical and sexual assaults, and abandonment, especially in the elderly, the economic or patrimonial abuse by relatives or other people outside the family is added. The biological, psychological and social vulnerability 
of the elderly, as well as the fact that they aren`t always self-sufficient, favors mistreatment, because they depend on the care of other members of their family or third parties.

In recent years and since the Second World Assembly on Aging of the United Nations, as well as the International Plan of Action of Madrid on Aging, (Madrid, 2002), the international community has raised the abuse of the elderly as a matter of concern of human rights, recognizing it as a social problem that affects them worldwide and that has physical, psychological, social, medical, legal and ethical consequences.

Violence against older adults was one of the last problems to be recognized and has now become a serious social and public health problem. In Mexico, a prevalence between 8.1 and $18.6 \%$ is estimated. The objective of this research is to identify the level of prevalence and risk factors of mistreatment in older adults.

\section{Mistreatment Of Elderly People:}

The mistreatment of the elderly refers to any action or omission that causes harm and that violates the respect for their dignity and the exercise of their rights as a person. It can be done intentionally, but it can also happen due to unintentional ignorance. Abuse can occur in the family, community or institutional environments. Violence against the elderly can take many forms and occurs in all social, economic, ethnic and geographical atmospheres, therefore, it`s much closer and present than we imagine.

On the other hand, the World Health Organization defines it as "any isolated or repetitive act or lack of appropriate action, occurring in any relationship from which trust is expected, which causes harm or discomfort to the elderly person".

\section{Types Of Mistreatment:}

Physical abuse. It`s defined as the physical damage or coercion that causes physical or psychological injury. This can include; inflicting physical pain or intentionally depriving the patient of the services necessary to maintain physical and mental health, assaults that harm their physical integrity and that are made with the intention of provoking pain, injury or both (pushing, shaking, slaps, blows, cuts, burns, bindings, can be accompanied by physical and emotional isolation).

Psychological abuse: Intentional acts that produce mental or emotional discomfort to a person, such as verbal aggression, isolation, intimidating threats, humiliation, lack of respect for their beliefs, ridicule and any other degrading behavior, abandonment threats, or sending someone to an establishment for a long time, without their consent, lack of consideration of their desires and overprotection that generates feeling of uselessness or limits their ability to decide. This action can cause damage to the psychological health, the ability to decide, the loss of selfesteem and deterioration of their well-being.

Economic abuse: The use of the retirement pension of an elderly person or a part of it, for their own benefit, as well as the appropriation of goods, property or heritage in general, through fraud, deception or threats. This type of abuse can be observed when the person is suffering an eloquent deterioration with respect to his socio-economic level, such as change in clothing, having less money than usual, the transfer of his things inside his own house ordered by a third party. The OMS defines economic abuse as the illegal or improper exploitation or use of funds or other resources of the elderly.

Negligence: Negligence is another form of abuse that turns out to be constant and in some sources it`s reported as the most frequent. It's the failure of the caregiver to provide food, water, clothing, comfort, safety, access to health services and protection against abuse or exploitation. It manifests itself in patients with bad nutrition or weight loss, poor hygiene, inappropriate or inadequate clothing, bad smell, repeated infections, pressure ulcers, anxiety or depression and unexpected clinical deterioration that could suggest a lack of medication or treatment. In addition, it may be evident in those who lack assistive devices needed to stay alert around them, such as walkers, glasses, dentures, hearing aids, among others. Without these, this population is susceptible to falls, fractures and decreased functional capacity, which increases morbidity and mortality. This type of negligence can be passive, when it is the consequence of a lack of knowledge or incapacity on the part of the caregiver. Instead, it becomes active when it's done intentionally. 
Abandonment: It occurs when any person or institution doesn't assume the responsibility that corresponds to him in the care of an older adult, or that, having assumed his care or custody, forsakes voluntarily.

Sexual abuse: Performing sexual acts with an older person without their consent, using force, threatening or taking advantage of the existence of a cognitive impairment that makes them incapable of giving such consent.

\section{Other Types Of Mistreatment To Elderly People:-}

Ageism: It consists of the presence of stereotypes and negative attitudes and / or the discrimination of a person based on their age, being able to favor the performance of discriminatory practices by society, and even more transcendental if it's on the part of professionals, especially if they are dedicated to the exercise of geriatrics or gerontology. It isn't uncommon to associate the elderly with illness, inactivity, economic and / or social burden, asexuality and you can still hear some professionals in the consultations say "what do you want for your age?" before the requirement of any discomfort or pathology.

Syndrome of the slave grandmother: It's a serious illness that affects older women with excessive direct responsibilities as a housewife, caregiver and educator, functions assumed voluntarily with pleasure for many years. It's characterized by the high degree of chronic suffering it causes, with great deterioration in the quality of life.

Diogenes syndrome: It's a communication isolation behavior with breakdown of social relationships, neglect of basic needs (such as hygiene, food, health care or clothing), home confinement rejection of aid and denial of the pathological situation; It usually occurs in lonely people. It's therefore a form of self-abuse.

Physical containment: Any method, applied to a person, that limits their freedom of movement, physical activity, or normal access to any part of their body. Their practice should be limited to the maximum, if possible to zero, and as an exception only in cases of risk to the life of the person if there is no other way, and always under the prescription of the interdisciplinary team and with the family`s permission.

Chemical or pharmacological containment: The inappropriate use of psychotropic drugs, sedatives or tranquillizers, to manage or control annoying behavior, which isn`t based on a diagnosed psychiatric disorder. It's about the use of these medications to handle a problem, for which there is a better treatment. It must always be prescribed by a doctor, with it's proper doses, and based on a pathology that justifies it, and never for complacency. This isn't always true. It's use isn`t infrequent in the face of annoying behaviors without medical prescription, or increasing it`s doses, both in institutions and in homes.

Points Of Incidence Of Mistreatment: The mistreatment of the elderly is exercised by society itself, in which a negative and stereotyped image of old age prevails, which tends to value youth over experience and therefore discriminates against them. On the other hand, it has been pointed out that when they become dependent on the care of others, both in the family and in an institution, they become more vulnerable to situations of abuse.

In the family: The abuse of the elderly in the family, or intrafamily violence (FIV), occurs when it's usually perpetrated by some of its members who are usually the caregivers. It's recognized in many studies that domestic abuse is often hidden, it's not easy to detect, it's not reported in most cases and it occurs as a result of social and economic tensions, greater fragility and dependencies of older adults, changes in the role of the family and intergenerational differences, stress of the caregiver. The types of abuse in the family refer to psychological abuse, neglect, abandonment and patrimonial abuse.

In institutions: It refers to any form of abuse or violence that occurs in services for older adults (public services, municipalities, long-stay facilities, primary health care centers, hospitals). Those who comment on the abuse are usually people who have a legal or contractual obligation to provide the services, care and protection of those who come to these establishments. This type of abuse is related to the deficiencies in the various care systems, including insufficient services, lack of staff training, a single window of attention, overload, poor attention or discriminatory attention based on prejudgement and stereotypes of old age.

In long-stay facilities for older adults: One type of institutional abuse is the one that is exercised in some longstay facilities for older adults (ELEAM). There are especially vulnerable older adults, mainly because of the severe 
dependencies they present. The types of institutional abuse that can occur more frequently in these types of establishments are:

Infantilization: Treat the elderly as a child limiting their capacity of autonomy.

Depersonalization: Provide services according to general criteria that disregard their individual needs.

Dehumanization: Ignore it, deprive them of their privacy and their capacity for autonomy.

Victimization: Attacks on the physical and moral integrity of the elderly, through threats, intimidation and verbal attacks, robbery, blackmail, or corporal punishment.

Negligence: Not deliver the necessary care or supervision of food, clothing, hygiene or medical care that are required.

\section{Risk Factors Of Mistreatment In The Elderly:}

The causes of elder abuse are diverse and complex and include individual, family, social and cultural factors. Due to its difficulty in finding the risk factors, it is necessary to look for the affected person (older adult person), the person responsible (the mistreator) and the environment (relationships, economic and social characteristics). The interaction of the factors in the three domains that interact determines the level of risk of abuse.

The causes of elder abuse are diverse and complex and include individual, family, social and cultural factors. Due to its difficulty in finding the risk factors, it is necessary to look for the affected person (older adult person), the person responsible (the mistreator) and the environment (relationships, economic and social characteristics). The interaction of the factors in the three domains that interact determines the level of risk of abuse.

Risk factors can be defined as experiences, behaviors, lifestyle, environment, or personal characteristics that increase the probability of abuse. It's important to know the risk factors of elder abuse for several reasons. In the first place, it`s necessary for the development of detection methods, since the effective finding could reduce the negative effects of this phenomenon. Second, it represents information of utmost importance to create prevention programs. Third, it`s essential for the development of public policy, since it`s necessary to identify the populations at greatest risk and the causes of this greater risk.

Risk factors for elder abuse can be classified into three groups.

1. Probable risk factors: when there is unanimous or almost unanimous support in several studies

2. Potential risk factors: when the support, on the part of the studies, is contradictory or limited.

3. Questionable risk factors: when it is assumed that they increase the probability of abuse, but there is no empirical evidence to support it.

\section{Theories That Explain The Abuse Of The Elderly:}

Stress of the Caretaker: The role of caregiver can be an extreme experience, with a great burden of stress and frustration, usually the caregiver doesn't have the support of others, access to information from social programs and isn`t prepared to adequately perform the care task (it can increase the caregiver`s stress aspects such as performance, economic problems and overcrowding, among other factors.)

Dependence or Disability of the Elderly: Caring for a dependent elderly increases the caregiver's burden and stress. Several studies have found that individuals with deteriorating health are more likely to be abused than those with better health, on the other hand, caregivers who depend financially on the elderly tend to be more abusive.

Social isolation: The stress produced by low social contact can increase the caregiver's predisposition to violence. The elderly victims of abuse have less social contact, compared to those who don't suffer abuse, likewise their social relationships are less satisfactory (social support affects the physical and psychological well-being of the family and reduces stress).

Social Learning: Like gender violence and child abuse, the theory of social learning emphasizes the role of the family in learning behaviors that are perpetuated and that the individual will perform throughout his life. Violent behavior is a violent mechanism to express anger and frustration. 
Social Disadvantage: This theory highlights the impact of society on the lives of older adults, who feel marginalized by their environment. Many of the problems that exist in older adults aren`t consequences of biological or natural processes of the aging process itself but reflect the social inequalities that limit their roles and resources.

\section{Method:}

The study of this research is descriptive, with a quantitative, transversal approach. The sample is 60 elderly people from different institutions, the instrument that was applied was the Geriatric Scale of Elderly Abuse.

\section{Instrument:}

The Geriatric Scale of Elder Abuse consists of five sections: physical, psychological, negligence, economic and sexual.

\section{Process:}

We proceeded to the delivery of an informed consent letter where the reason for this investigation was explained. Once the authorization was obtained, the Geriatric Scale of Elder Abuse was applied in different institutions, the results were analyzed and obtained through the Statistical Program SPSS.

\section{Results:-}

From the analysis of the data the results obtained are mentioned below:

Graphic one tells us that in older adults the 60 people who applied the test in physical abuse, 51 older adults commented that they have not been beaten and 9 said yes, 55 people commented that they have not punched or kicked 54 of them, they said they have not pushed or pulled his hair, 3 of the older adults said they have not thrown an object and 58 of them say they have not assaulted him with knives or razor only two of them said yes.

In this graphic about psychological abuse he tells us that 32 elderly people have not humiliated him and 28 says that at some point if they have been mocked, they have treated them with indifference 30 of them, 47 say they have not made him feel fear and 22 have respected his decisions (graph two).

In graphic 3 on Negligence, 53 older adults commented that no they have stopped providing clothes, shoes, among others and 7 of them say that if and if they have stopped providing the medication they need, 45 answered no, but 6 of them say yes, in the question, have they denied protection when they need it? 57 older adults say no and 3 yes, they have denied access to the house they live in 59 they said no and only one said yes.

In graphic 4 Economic mistreatment, 55 older adults commented that not in the question has someone managed or handled their money without their consent? And 5 said yes, their money has been taken away 49 older adults said no and 11 said that if this information is significant, in the question, have they sold any property belonging to them without their consent? the 60 older adults answered no, which means that they are taken into account for their consent and in the question, have they pressured you to stop being the owner of your house or some other property? 59 said no and only 1 said yes.

In Sexual Abuse, which is located in graphic 5, two questions were asked: have you been required to have sexual relations, even if you do not want to? And have your genitals been touched without your consent? It was agreed that the 60 older adults answered no, which means that this type of abuse does not exist in the older adults who were surveyed. 


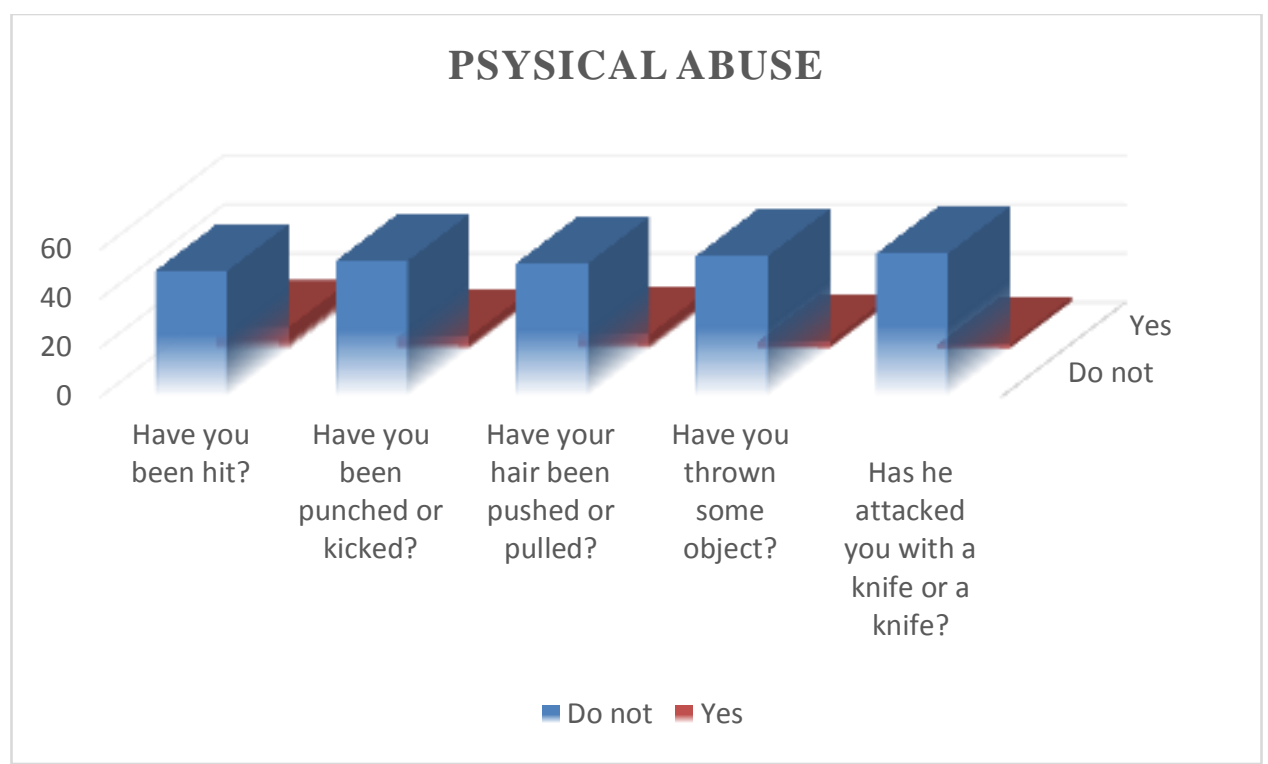

Graphic 1:- Physical abuse

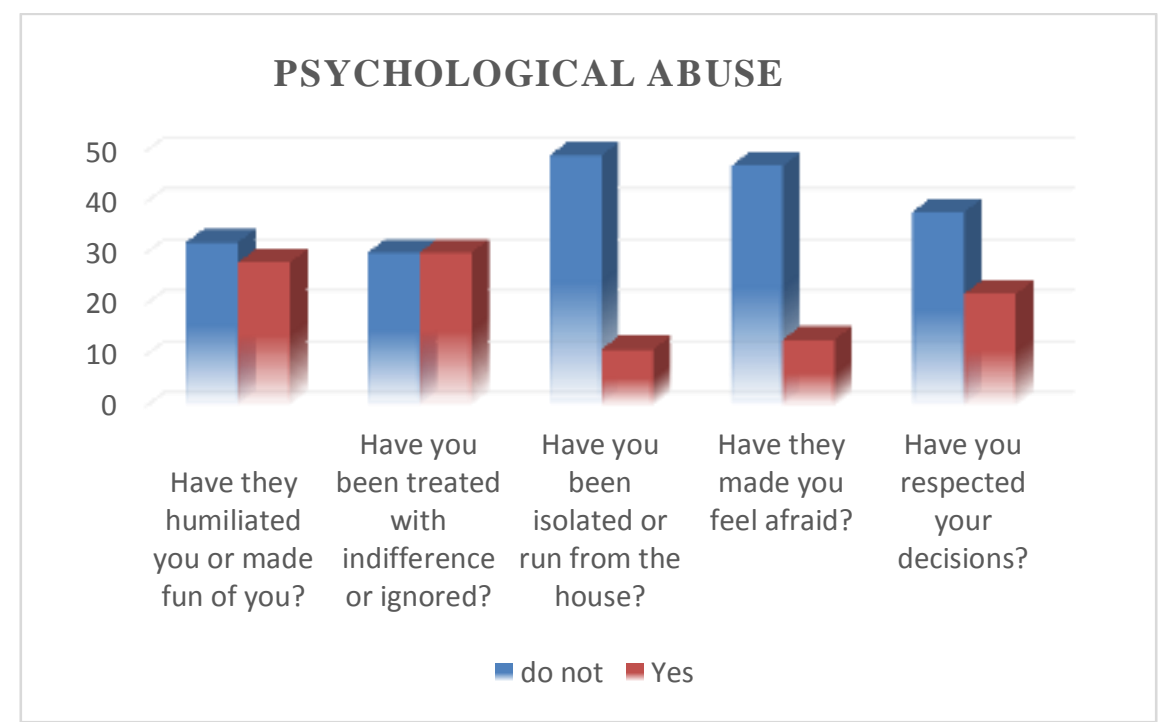

Graphic 2:- Psychological abuse 


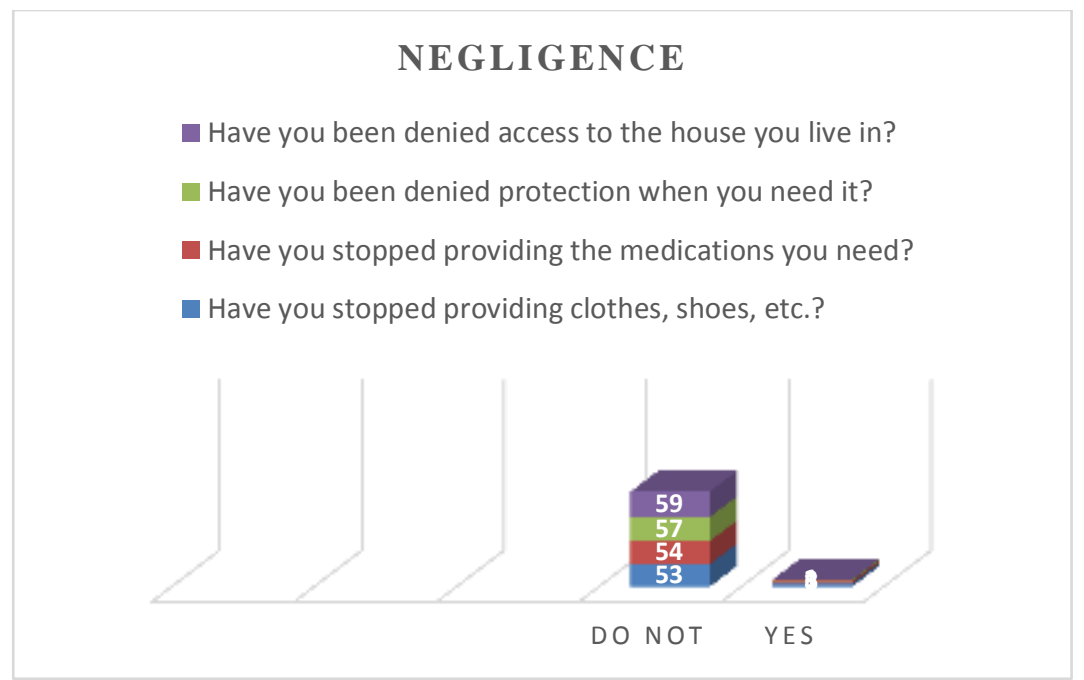

Graphic 3:- Negligence

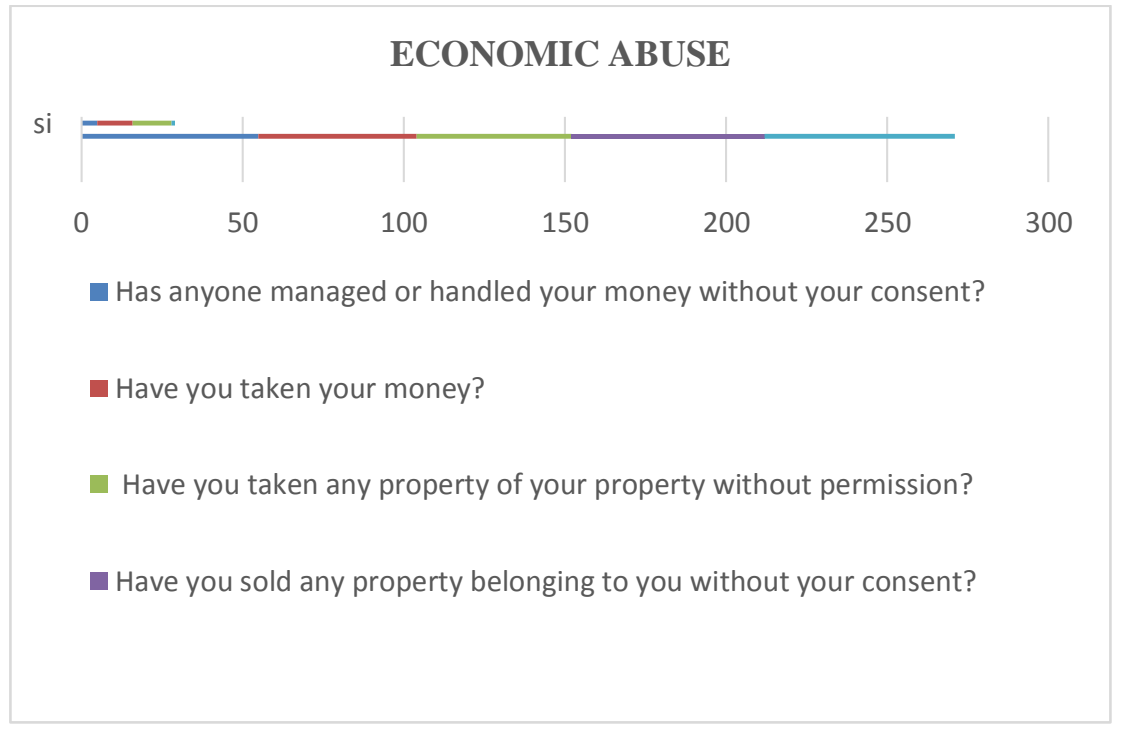

Graphic 4:- Economic abuse 


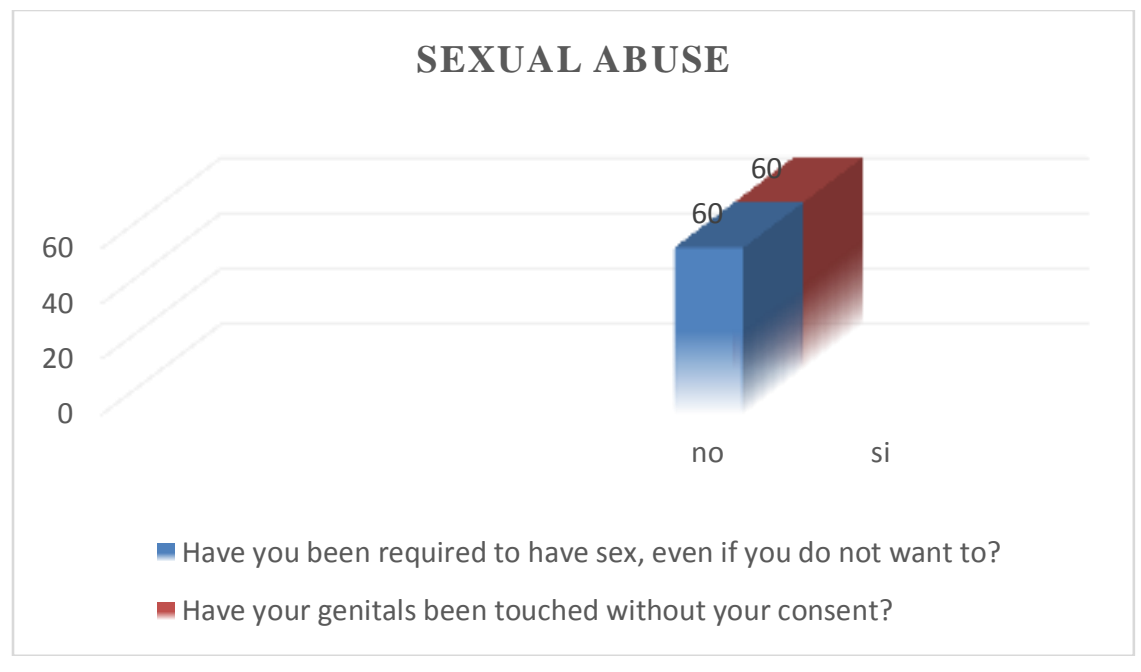

Graphic 5:- Sexual abuse

\section{Conclusions:-}

As a final result of this investigation, we found that $25 \%$ of older adults belonging to a governmental institution in the state of San Francisco de Campeche have some type of abuse. Of which the psychological abuse was the most prevalent with $40 \%$. Therefore, the aim is to create training programs in the institutions for staff and family members who deal directly and indirectly with older adults in order to reduce the percentage of this social problem that affects older adults more every day.

Among the main risk factors of abuse are:

1. Alterations in the psychological behavior of the elderly person.

2. Neurocognitive deficit (Alzheimer's, dementia, deterioration at the conscience level)

3. Physical problems (incontinence and insomnia).

Stress of the caregiver that affects the relative or the caregiver in charge of the older adult due to the lack of support, and personal dissatisfaction, change in the rhythm of life, family conflict, fatigue, sadness due to the deterioration of the other person).

\section{References:-}

1. Montero G. alt. (2017). Abuse and Abuse in the Elderly. Costa Rica. Virtual Costa Rica legal medicine Editorial. file: /// C: /Users/Juan\%20S/Documents/maltrato/definicion\%20de\%20scielo.pdf

2. Giraldo M. alt. (2016). Surveys on Elder Abuse in the Federal District. file: I/I C: /Users/Juan\%20S/Documents/maltrato/analisis_EMPAMDF\%20maltrato.pd

3. Kornfeld R. alt. (2012). How to Prevent and Face the Abuse of the Elderly. file: /I/ C: /Users/Juan\%20S/Documents/maltrato/Cartilla\%20SENAMA.pdf

4. WHO (2002). University of Toronto and Ryerson, INPEA. "Toronto Declaration for the global prevention of elder abuse". Special journal of geriatrics and gerontology, 37. pp.332-333

5. Gómez R, L; Rodríguez AG and Krug L. "Prevalence and Factors Associated with Family Violence in Older Adults of Ocozocoautla (Chiapas, Mexico)". Rev esp geriatr gerontol.2007; 42 (1): 27-34

6. Giraldo, L. "Elder Abuse: A look from a gender perspective". Feminist debate magazine. 2010; 21 (42): 151165

7. Clinical Practice Guide: Detection and Management of Elder Abuse. Mexico: Mexican Institute of Social Security, 2013. file: /// C: /Users/Juan\%20S/Documents/maltrato/maltrato\%20en\%20la\%20seg.pdf

8. Hernández R. alt. (2010). Investigation methodology. México. Editorial Mc Graw Hill. Fifth edition 